\title{
Soap Production Using Waste Materials of Cassava Peel and Plantain Peel Ash as an Alternative Active Ingredient, Implication for Entrepreneurship
}

\author{
Umeh-Idika Adaku and Maduakor Melody \\ Home Economics/Hmt Department Michael Okpara University Of Agriculture, Umudike
}

\begin{abstract}
The study was conducted using plantain peel ash and cassava peel ash as an active ingredient. These peels are agricultural waste materials that litter the whole environment. The study used the peels as alternative source to the much needed lye, in soap making. The usage of these peels will reduce the cost of soap making and also reduce waste materials in our environment and these will reduce diseases caused by these waste. The plantain peels and cassava peels were burnt into ashes and the ashes were turned into solution with water and filtered. The filtrate was boiled with palm kernel oil, until good lathering soaps were obtained, sensory evaluation was conducted using 15 home Economic respondents. The data were analyzed using frequency distribution and percentage. The qualities of the soap evaluated were the colour, odour, lathering ability and texture. The findings showed that the ashes were good alternative, ingredient for soap making. Recommendations were made based on the findings: that the use of the raw materials should be encouraged for soap making to save the country's foreign exchange. There is need to create awareness on the use of the ashes. Home economics graduates should exploit the self employment opportunity in the area of local soap production using these ashes for self-reliance.
\end{abstract}

\section{Introduction}

Homemade soap using local raw materials is an ancient and amazing method that is used in producing soaps for the family use in the olden days. Technically, soap making involves the use of sodium salts (Isaac, 2005). Aesthetically, homemade soap is one of the soaps used in the family cleaning chores. But recently this skill of soap making is gradually fading away that the younger generation may not be able to enumerate the ingredients in soap making not to mention making the soap itself. The making of soap using vegetable matter has been an age old craft, unfortunately the soaps that were made then, were soft, black, smelly and corrosive to the hands. So there is need for improvement which the study is all about.

Soap is one of the cleaning materials needed by every family (Anyakoha, 2011). Soap is so important that there is hardly any family that does not use it in their daily activities either in the solid bars, liquid and detergent forms. Soaps are salts of fatty acids and it may be hard or soft soap depending on the type of ingredients used (Okeke, 2009). Soaps are made by the hydrolysis of fats with caustic soda (Sodium hydroxide), thus converting the glycosides of stearic, oleic and palmitic acids into sodium salts and glycerol. Soaps have a cleansing action because they contain negative ions composed of a long hydrocarbon chains attached to a carboxyl group (Okeke, 2009). The hydrocarbon chain has an affinity for grease and oil and the carboxyl group has an affinity for water. That is why soaps are mostly used with water for bathing, washing and cleaning. They are also used in textile industries for textile spinning. Soaps often occur in form of solid bars or liquid form.

There are many agricultural waste materials generated in homes and littered all over the environment. These materials include palm bunch, coco-pod, plantain peels, banana peels, maize cobs, cassava peels and others. Some of these agricultural waste like coco-pod are adverse to soil fertility and so constitute environmental nuisance to man. So they are a potential viable source which needs to be harnessed for other uses and to save the environment. According to Adewuji, Obi-Egbado and Babayemi (2008), several agricultural wastes of vegetable origin yield a high potash when combusted. These materials include plantain peels, cassava peels, palm bunch, wood and others. The local production of potash from these agricultural wastes has been observed to be a cheaper alternative source of this much needed chemical used in the production of soap and other alkalis based products (Adewuji et al, 2008). While Onyegbado, Iyagba and offor (2004) has observed that alkali content of potash obtained from ashes of plants origin were high and good for soap production.

Presently, the art of homemade soap using caustic soda is gaining acceptance because of emphasizes on entrepreneurship education in our educational system. Production of soap using agricultural wastes is a veritable source of gainful employment for individuals. Soap is one of the most essential needs of man used for several purposes. Therefore, soap made with potash characteristically provide fulfillment to the important need 
of man for maintaining cleanliness. However, in spite of the popularity of homemade soaps and the benefits of its production, homemade soap has not been given the adequate attention that it deserves by students of home economics. Similarly, its potentials as a medium for showcasing creativity is not fully being exploited. Also the concern of this study equally is the fact that the production of homemade soap is a very viable business opportunity for self employment, which home economics graduates can exploit. The recent emphasis on entrepreneurship in our educational institutions makes it imperative that opportunities that can be exploited for self-employment should never be neglected. Thirdly, several agricultural wastes are littered all over the environment and accumulation of these wastes poses a serious health hazard apart from being an eyesore. Throwing away some of these agricultural wastes is a waste of resources which are potential source of raw materials needed to soap making and also the disposal is a waste of hidden treasure. Therefore, such agricultural wastes could be converted to potash used for soap making.

\section{Purpose of the study}

The main purpose of this study was to produce soap using cassava peels and plantain peel ash as active ingredients. Specifically, the study determined;

1. Potassium hydroxide $(\mathrm{KOH})$ concentrations of plantain peel and cassava peel ashes?

2. the acceptability of the soap made with potash from plantain peel ash and cassava peel ash.

\section{Research questions}

The study was guided by the following research questions;

1. What are the potassium hydroxide $(\mathrm{HOH})$ concentrations of plantain peels and cassava peels?

2. What is the general acceptability of soap made with plantain peel and cassava peel ash?

Area of the study

\section{Materials And Methods}

The area of the study is Michael Okpara University of Agriculture, Umudike.

\section{Design of the Study}

The study adopted experimental design. The experiment were carried out in the laboratory of College of animal production to determine the acidity of the ash. The soap was produced in the clothing laboratory of Home Economics Department, College of Applied Food Sciences and Tourism, Michael Okpara University, Umudike.

\section{Preparation of ash}

Gather the plantain peels and cassava peels, separate the dirt from the peels, dry in the sun for two weeks until it is properly dried. Burn the peels separately until properly burnt, gather the ashes into a clean container and store.

\section{Determination of potash concentration of the ashes}

- $5 \mathrm{~g}$ of plantain ash

- $5 \mathrm{~g}$ of cassava ash

- $200 \mathrm{mls}$ of distilled water

- Methyl orange

- 2 filter papers

- $0.1 \mathrm{~m}$ of $\mathrm{N}_{\mathrm{a} 2} \mathrm{C}_{03}$

- $0.5 \mathrm{~m}$ of $\mathrm{Hcl}$

\section{Laboratory equipment}

- Pipette

- Biurette

- Conical flasks

- Retort stand

- Beakers

- Glass stirrer

\section{Procedure for Titrations}

- $\quad$ Measure out $100 \mathrm{mls}$ of distilled water into each of the beakers

- Add 5g of each ash into the two beakers and stir properly 
- Boil the solutions, allow to cool, very well and filter it with filter papers separately

- Measure out $25 \mathrm{mls}$ of HCL with the burette

- Take $2 \mathrm{mls}$ of each solution and put in a clean conical flasks, add a drop of methyl orange

- Titrate until the colour changes to pink. This shows that the concentration is high.

\section{SOAP MAKING PROCESS}

Materials and equipment

- $\quad 1 / 2$ litre palm kernel oil each

- $\quad 200 \mathrm{~g}$ of each ash

- 1 roll of bigger cotton wool

- Baft cloth

- 4 litres of water

- Perfume

- 2 metal pots

- 2 big plastic bowl

- Wooden stirrer

- $\quad 2$ aluminum moulds (soap)

- Sharp knife for cutting

\section{Soap preparation method}

- Measure out 2 litres of water into each bowl

- Weigh out $200 \mathrm{~g}$ each of the ashes into the bowls containing the water and stir each very well

- Strain each solution through a baft cloth to remove large sediments

- Use the cotton wool to filter the solution again until it is clear

- Boil the potash solutions in separate open pots to get concentrated solutions of the potash

- While the potash is still on fire pour in the palm kernel oil a little at a time

- Stir continuously with a wooden stirrer until it is properly saponified

- Remove from heat

- Pour the mixture into the cleaned aluminum moulds and leave to harden for at least 24 hours. Designs can be added at this stage before final hardening

- When properly cooled, the soap will take the shape of the mould

- Cut the soaps for evaluation

\section{Findings of the study}

The findings of the study were summarized as follows;

1. The potassium hydroxide $(\mathrm{KOH})$ concentrations of plantain peel is very high while that of cassava peel is low. It was observed that both contain potassium hydroxide $(\mathrm{KOH})$ in different degrees of alkalinity. The plantain peel is moist alkaline than the cassava peel, because both of them are alkaline in nature they were found to be suitable for soap making.

Table 1:

\begin{tabular}{|l|l|l|}
\hline Samples & Concentration of KOH & pH value \\
\hline Plantain peel ash & $64.57 \mathrm{~g} / \mathrm{dm}^{3}$ & 11.31 \\
\hline Cassava peel ash & $4.82 \mathrm{~g} / \mathrm{dn}^{3}$ & 9.17 \\
\hline
\end{tabular}

Table 2: The general acceptability of the soaps by the panelist showed:

\begin{tabular}{|l|l|l|l|l|l|l|l|}
\hline & Rating & CSS & $\%$ & PPS & $\%$ & CPS & $\%$ \\
\hline 9 & Likes extremely & 7 & 46.6 & 4 & 26.6 & - & - \\
\hline 8 & Like very much & 5 & 33.3 & 5 & 33.3 & 5 & 33.3 \\
\hline 7 & Like moderately & 1 & 6.7 & 4 & 26.7 & 5 & 33.3 \\
\hline 6 & Like slightly & - & - & 1 & 6.7 & - & 20 \\
\hline 5 & Neither like nor dislike & 1 & 6.7 & 1 & 6.7 & 1 & 6.7 \\
\hline 4 & Dislike slightly & 1 & 6.7 & - & - & - & - \\
\hline 3 & Dislike moderately & - & - & - & - & 1 & 6.7 \\
\hline 2 & Dislike very much & - & - & - & - & - & - \\
\hline 1 & Dislike extremely & - & - & - & - & - & - \\
\hline & & 15 & 100 & 15 & 100 & 15 & 100 \\
\hline
\end{tabular}

\section{Codes used in the table}

$\begin{array}{lll}\text { CSS } & - & \text { Control soap (caustic soda) } \\ \text { PPS } & - & \text { Plantain peel ash soap } \\ \text { CPS } & - & \text { Cassava peel ash soap }\end{array}$


In the table 2 above $45.6 \%$ extremely accepted CSS and 26.6\% extremely accepted PPS while $33.3 \%$ accepted PPS very much and CPS moderately. The general acceptability showed that CSS is more accepted than PPS and CPS while CPS had the least acceptance. See appendix I.

\section{Discussion of findings}

Several waste materials such as plantain peel, cassava peel, palm bunch, coco pods etc have been shown to yield high percentage of potash which is suitable for soap making. It was also discovered that the process of combustion contributes to the quality of the potash. When the peels are slowly combusted they will not burn completely and this affects the concentration of the potash (Kirk and Othmer, (1994). The findings of the study revealed that plantain peels ash has higher concentration of potassium Hydroxide (KOH) than cassava peel ash. The result of the laboratory analysis of ashes of plantain peels and cassava peels to produce alternative source of caustic soda for soap making is in line with the works of Kirk and Othemer (1994). The Hedonic scale of rating was used to evaluate different qualities of plantain peel and cassava peel ash soaps in terms of their texture, colour, odour lathering ability and general acceptability.

The data collected during analysis showed that, the respondents liked the soap samples very much. This is as a result of improved colour, texture, odour and lathering quality. The soap when made with well filtered ash solutions and palm kernel oil has improved colour and increase lathering ability as was observed from the sensory evaluation on colour that $33.3 \%$ of respondents extremely liked the colour of plantain peel ash soap and $20 \%$ liked the colour of cassava peel ash soap very much. All these are in agreement with the findings of Onyeghado et al; (2000) that clearer filtration in the extraction stage, virtually removed all black particles from the extract and also eliminates any methallic ions in the ash extract, which could colour the resulting soap. The findings of this study is of the view that the colour improvement observed by the panelists were as a result of filtering the alkaline solutions with cotton wool and also the use of palm kernel oil (PKO).

The findings also revealed that the lathering ability of the soaps were generally liked by the respondents, this is due to the fact that the ashes contain very high quantity of alkali which when completely saponified with palm kernel oil lathers very well. This is in line with Onyekwere (1996), who observed that soaps made with alkalis derived from vegetable matter ashes when reacted with palm kernel oil and always been soft and had good lathering abilities and cleaning properties. The odour of the soap was improved with the use of palm kernel oil and perfume, this in agreement with Onyekwere (1996) who stated that bleaching the oil removes the characteristic odour of palm oil in the soap produced.

The result obtained from the sensory evaluation on the general acceptability of the respondents showed that the soap were generally accepted by the panelist because of the improvement on the colour, odour, texture and lathering ability which was achieved with the use of palm kernel oil, clearer filtration of the solutions and the added perfume..

\section{Conclusion}

The production of local soap using ashes is a cheap method which if well explored and improved could meet the need for raw materials used in soap production. Although, the study showed significant acceptability of the soaps, there is still need for further improvement in the colour, texture and standardized mould and cutlers to enhance the aesthetic quality of the soap. As a result of this wide acceptability of the locally made soap by respondents individuals can successfully establish soap making business using this raw materials which will receive good patronage and hence be self-reliant. This will impact positively on the unemployment problem in the country.

Based on the findings, the study recommended that;

\section{Recommendations}

- The use of raw materials from vegetable matter should be encouraged for soap production to save the country's foreign exchange.

- There is need to create awareness of using plantain peel ash and cassava peel ash solutions as alternative source to caustic soda.

- The right type of filter should be used to filter the ash very well to have clean soaps.

- Home economics graduates should exploit the self-employment opportunity in the area of local production of soap for self reliance. 


\section{References}

[1]. Adewuji, G. O. Obi-Egbedo, N. O and Babayemi, J. O., (2008). Evaluation of ten different African wood species for potash production. International Journal of Physical Sciences 3; 63-68.

[2]. Amyakoha, E. U (ed) (2009). New Entrepreneurship education and Wealth Creation Strategies $2^{\text {nd }}$ edition. Practical tips for Economic Empowerment and Survival. Nsukka; Great AP Express Publishers ltd.

[3]. Anyakoha, E. U. (2011). Home Economics for Junior Secondary Schools. Onitsha: African-first Publishers Plc., Nigeria.

[4]. AOAC (1984). Official methods of analysis, association of official analytical Chemists, Washington DC, USA

[5]. Isaac, A. (ed.) (2005). The Macmillan Encyclopedia London: Published by Macmillan London limited.

[6]. Kirk, R.. E and Othmer, D.F. (1994). Encyclopedia of Chemical Technology ${ }^{\text {rd }}$ edition P. 573-589.

[7]. Okeke, S. U. N. 92009). Home economics for schools and colleges, Onitsha: Africana First publishers plc Nigeria.

[8]. Onyegbado, C.O., Iyagba, T. E and Offor O. J. (2004). Solid soap production using plantain peels ashes as a source of alkali. Journal of Applied sciences and Environmental management 6; 73-77.

[9]. Onyekwere, C (1996). Cassava peels ash: An alternative source of caustic soda production. Unpublished B. Eng. Thesis. Department of Chemical Engineering, University of port Harcourt, Nigeria.

\section{APPENDIX I}

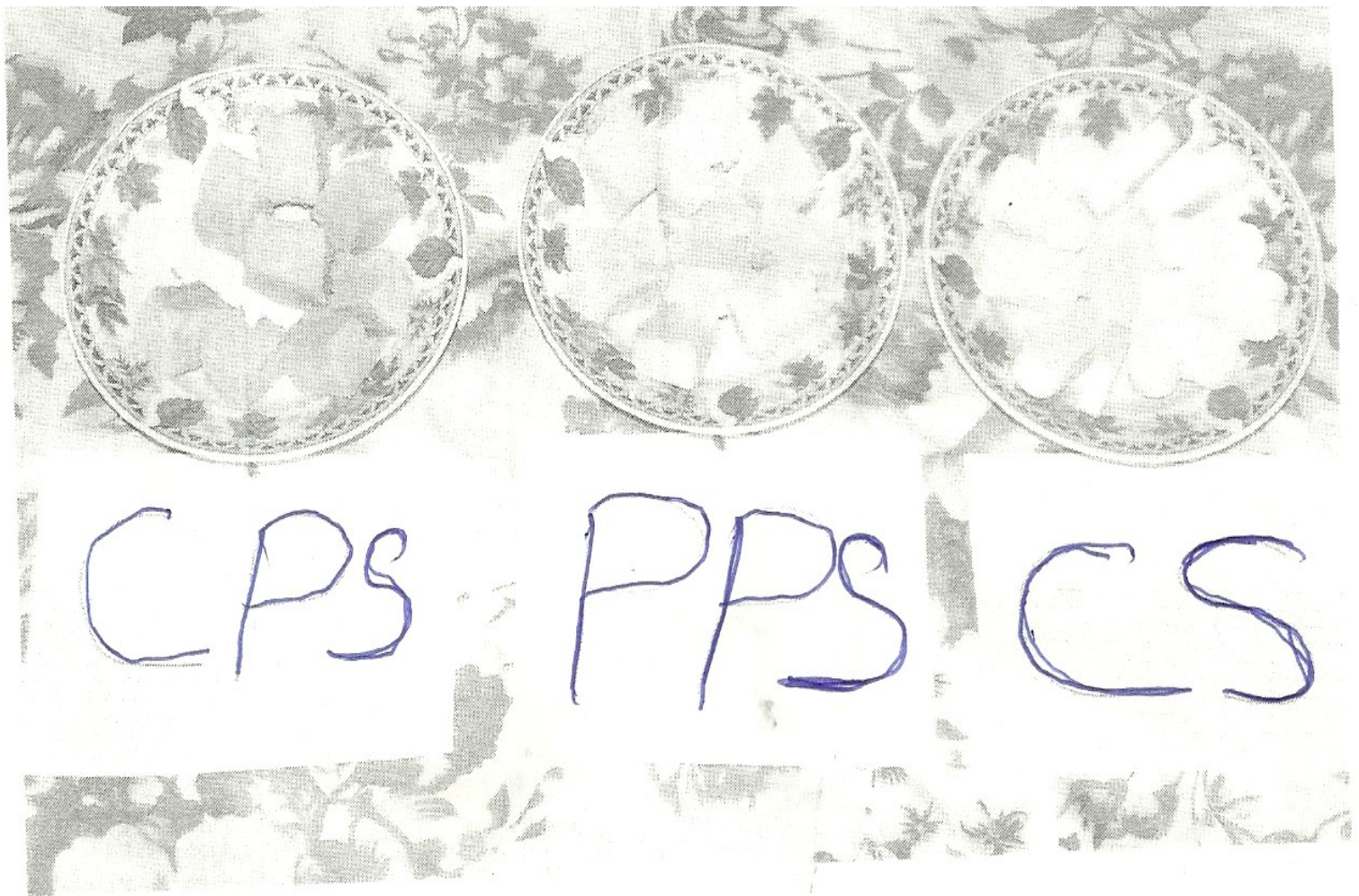

